\title{
Health-related quality of life and leisure physical activity during
}

\section{pregnancy}

http://dx.doi.org/10.11606/1807-5509201700030629

\author{
Ana Claudia HIRASAWA* \\ Simone Cristina SCARPA ROMERO* \\ Carolina Harumi KURASHIMA* \\ Florence Cousson GELIE** \\ Monica Yuri TAKITO* \\ *Escola de Educação
Física e Esporte,
Universidade de São
Paulo, São Paulo, SP,
Brasil.
**Epidaure/lnstitut
du Cancer de
Montpellier, Université
de Montpellier,
Montpellier, França.
}

\begin{abstract}
The practice of physical activity during pregnancy plays an important role related to improvement how women perceive their health status. The aim of this study was to investigate the relationship between perceived quality of life during pregnancy and the practice of physical activity during leisure time. It is a cross-sectional study of 187 postpartum women. A retrospective questionnaire was administered to obtain information regarding pregnancy, being evaluated the pattern of physical activity and health status. To evaluate the aspects related to quality of life we used the SF-12 questionnaire. The statistical analysis were $\mathrm{t}$-test, chi-square and multiple linear regression analysis. From the results it was observed that mothers who were active during pregnancy considered their good or excellent health compared do non active $(p=0.005$, $35.9 \%$ and $15.5 \%$ respectively). Active women had higher mental component when compared to those who did not practice $(p=0.035)$. There was a relationship between mental component with the private health service, income, education level, disease and presence of a partner. The physical component was related to maternal age, low birth weight, obesity, and smoking during pregnancy. Despite univariate analysis showed a positive association between physical activity during leisure time and the mental component of quality of life related to health, this association lost significance when included age and care health sectors. Longitudinal studies should be developed to measure effects of physical activity in quality of life.
\end{abstract}

KeYwords: Pregnant Women; Physical Activity; Quality of Life.

\section{Introduction}

The multidimensionality of the term quality of life has resulted in a body of knowledge that is broad and comprehensive ${ }^{1,2}$ despite the different interpretations. The temporary psychological and physical changes that result from gestation ${ }^{3}$ can affect a woman's quality of life perception, specifically when associated with physical and mental health. Physical activity during leisure time and exercise has beneficial effects on maternal and foetal health ${ }^{4}$ and has been positively associated with improvements in a woman's perceived quality of lifes.

The hypothesis that regular physical activity in leisure/exercise provides a better sense of "wellbeing" for pregnant women can be linked to reductions in oedema in the lower limbs and back pain ${ }^{6,7}$. Additionally, regular physical activity has also been shown to reduce insomnia, improve $\operatorname{mood}^{8}$, aid in cardiovascular conditioning and weight maintenance ${ }^{9}$ as well as reduce the person's risk for specific diseases such as gestational diabetes $^{10,11}$, preeclampsia ${ }^{12,4}$ and depression ${ }^{13}$. Moreover, physical activity has a protective and preventive role for fetal health and development ${ }^{14}$.

Regardless of all of the health benefits of physical activity during pregnancy, studies show that many women are still unaware of the recommendations and have a sedentary behaviour for more than half their pregnancy resulting in them performing less physical activity than they should ${ }^{15}$. 
More broadly, a population-based study showed that physical activity levels decrease during pregnancy. The observed decrease in physical activity during pregnancy is associated with biological (fatigue and the presence of diseases) and social factors (education, income and number of children) as well as the lack of knowledge regarding the recommendations for physical activity during pregnancy ${ }^{16}$.

Although studies conducted on the general population showed a positive association between regular physical activity in leisure time and the perception of one's quality of life, a small number of studied this period. TendaIs et al. ${ }^{17}$ noted that in both the first and second trimester of pregnancy, active women had a better perception of their quality of life (physical and mental components) than sedentary women, despite the small sample size and the lack of identification of other factors and characteristics of the samples.

Thus, the aim of this study was to investigate the relationship between a woman's perceived quality of life during pregnancy and the practice of leisure time physical activity by comparing public and private health services.

\section{Method}

This study was a cross-sectional study that evaluated a sample of 187 postpartum women. Women between 18 and 45 years old were included in the study. The exclusion criteria included women who had a chronic disease (diabetes mellitus, gestational diabetes, hypertension, pregnancyinduced hypertension and heart disease), multiple pregnancies or any condition leading to a reduction in physical activity or bed rest. Stillbirths, babies with congenital anomalies detected at birth or at risk were not included in the survey. This problem could affect the perception of women with a negative bias.

The study was conducted in the city of Santo André, in the greater São Paulo area. Data were collected in two hospitals. Specifically, one hospital was public $(n=92)$, and the other was a private network of prenatal care $(\mathrm{n}=95)$. This sample allowed include four variables in linear multiple analysis at $5 \%$ of significance and power at $80 \%{ }^{18}$ even at a lower effect women were interviewed one day after giving birth. A questionnaire was used to assess demographic, socioeconomic, anthropometric and physical activity at leisure time during pregnancy. The mothers were classified according to their nutritional status using the table provided by the World Health Organisation ${ }^{19}$. To evaluate the mother's perception of her quality of life, we used the SF-12, which aims to assess eight aspects that influence quality of life with issues divided into physical function, social function, paper physical, emotional role, mental health, vitality, bodily pain and general health. As a way to assess the intensity and frequency, all responses were assessed according to a Likert scale, with scores generating summaries of the components responsible for physical (Physical Component Summary - PCS) and mental (Mental Component Summary - MCS). All variables were derived from the sum of the weighted scores for each of the items, which allowed the scores to follow a standard pattern. This allowed the scores to then be compared to the values of the standard of the general population, which was $50(\mathrm{SD}=10)$, and the mean of the general population ${ }^{20}$.

The descriptive analysis was performed using measures of central tendency and dispersion. The categorical variables were compared using the chisquare test, and the t-test was used to compare continuous variables. To verify the components (mental and physical) and their associated factors, multiple linear regression models were used. The significance level was $\mathrm{p}<0.05$. However, for adjusted variables, the significance level was $p \leq 0.20$. Statistical analyses were performed using SPSS (Statistical Package for Social Sciences) v.21 and R (The R Project for Statistical Computing) v3.0.1.

All women who consented to participate in the present study signed an informed consent form approved by the Ethics in Scientific Research Committee and the local Department of Health of Santo André (013/2012). 


\section{Results}

The mean maternal age was 27 years $(\mathrm{SD}=6$ years), and the age of the women who participated in the study ranged from 18 to 41 years old. More than half $(61 \%)$ of the women worked outside the home, and the average per capita income of the group was $\mathrm{R} \$ 1,025.65$ ( $\mathrm{SD}=803.52)$. Regarding education levels, $14.8 \%$ attended primary school, $56.6 \%$ finished high school and $28.7 \%$ had some university education.

Overall, more than half $(89.5 \%)$ of the mothers lived with a partner and were not employed (61\%). With regard to lifestyle, the majority of the mothers did not use alcohol $(85 \%)$ or smoke $(84 \%)$ nor did they have any type of illness $(81.5 \%)$. Additionally, with regard to nutritional status, $46.5 \%$ of the women were overweight (body mass index $\geq 25 \mathrm{~kg} / \mathrm{m}^{2}$ ) and $49 \%$ were eutrophic.

Regarding leisure time physical activity, it was observed that only 39 (19.5\%) women practiced some type of physical activity during pregnancy, and $35.9 \%$ of those women remained active throughout the gestational period. On average, active women engaged in 30 minutes of physical activity per day
$(23.1 \%)$ or twice a week $(35.9 \%)$ and considered their struggles to be mild or minor (48.7\%). Among the physical activities performed, hiking was the most frequent activity (64.1\%).

Aspects of quality of life according to the SF-12 questionnaire are presented in TABLE 1 . When analysing health perception, as dichotomous variables, most of the mothers who were active during pregnancy considered their health to be excellent compared do non active $\left(X^{2}=8.06\right.$, $\mathrm{p}=0.005,35.9 \%$ and $15.5 \%$ respectively).

Mothers who practiced some physical activity showed the largest mental positive health component when compared to inactive mothers (TABLE 2).

When analysing the components to determine the factors (TABLE 3), beside practice LPTA, private prenatal care used by women during pregnancy, income, education level, the presence of pathology, having a partner and domestic activity were associated with mental health; physical health was influenced by age, being underweight, being obese and smoking during pregnancy.

TABLE 1 - Frequency and percentage of different aspects evaluated in SF-12 by physical activity. Santo André, São Paulo, 2012-2013.

\begin{tabular}{|c|c|c|c|c|c|c|}
\hline \multirow{3}{*}{ Questions } & \multicolumn{6}{|c|}{ Practice physical activity during leisure time } \\
\hline & \multicolumn{2}{|c|}{ No } & \multicolumn{2}{|c|}{ Yes } & \multirow[b]{2}{*}{$X^{2}$} & \multirow[b]{2}{*}{$p$} \\
\hline & $\mathbf{N}$ & $\%$ & $\mathbf{N}$ & $\%$ & & \\
\hline Perceived Health & & & & & 9.132 & 0.028 \\
\hline Excelent & 23 & 15.5 & 14 & 35.9 & & \\
\hline Very Good & 53 & 35.8 & 10 & 25.6 & & \\
\hline Good & 59 & 39.9 & 14 & 35.9 & & \\
\hline Regular & 13 & 8.8 & 1 & 2.6 & & \\
\hline Limitation to moderate activities & & & & & 2.949 & 0.229 \\
\hline Yes. limited / very difficult & 23 & 15.5 & 2 & 5.1 & & \\
\hline Yes. limited / difficult bit & 75 & 50.7 & 23 & 59 & & \\
\hline It does not limit any way & 50 & 33.8 & 14 & 35.9 & & \\
\hline Limitation to climb stairs & & & & & 1.641 & 0.440 \\
\hline Yes. limited / very difficult & 28 & 18.9 & 4 & 10.3 & & \\
\hline Yes. limited / difficult bit & 73 & 49.3 & 21 & 53.8 & & \\
\hline It does not limit any way & 48 & 31.8 & 14 & 35.9 & & \\
\hline
\end{tabular}


TABLE 1 - Frequency and percentage of different aspects evaluated in SF-12 by physical activity. Santo André, São Paulo, 2012-2013.

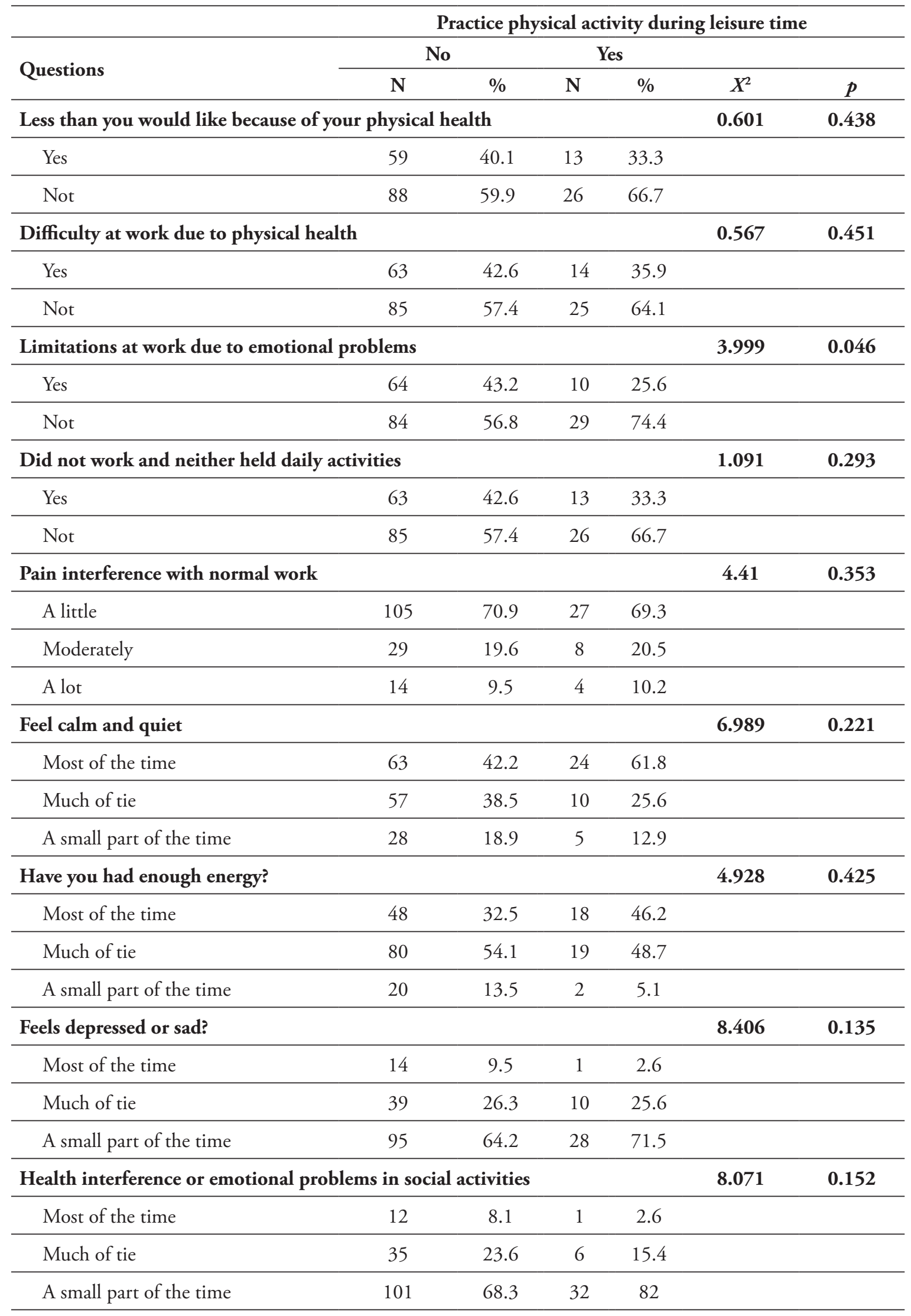


TABLE 2 - Mean and standard deviation of the physical and mental components, obtained from the SF-12, in relation to the practice of physical activity in leisure / exercise during pregnancy. Santo André, São Paulo, 2012-2013.

\begin{tabular}{|c|c|c|c|c|c|}
\hline \multirow{3}{*}{ Variables } & \multicolumn{4}{|c|}{ Practiced leisure physical activity / exercise during pregnancy } & \multirow{3}{*}{$\mathbf{p}^{*}$} \\
\hline & \multicolumn{2}{|c|}{ No } & \multicolumn{2}{|c|}{ Yes } & \\
\hline & Mean & SD & Mean & SD & \\
\hline \multicolumn{6}{|l|}{ Questionnaire SF-12 } \\
\hline Physical Component & 45.01 & 8.31 & 45.90 & 8.31 & 0.554 \\
\hline Mental Component & 46.68 & 8.53 & 49.81 & 6.92 & 0.035 \\
\hline
\end{tabular}

TABLE 3 - Estimates of the univariate model related to the physical and mental components. Santo André, São Paulo, 2012-2013.

\begin{tabular}{|c|c|c|c|c|}
\hline \multirow{2}{*}{ Variables } & \multicolumn{2}{|c|}{ Mental Component } & \multicolumn{2}{|c|}{ Physical Component } \\
\hline & Coefficient (SE) & $\mathbf{p}$ & Coefficient (SE) & $\mathbf{p}$ \\
\hline Establishment of sector (private) & $3.755(1.150)$ & 0.001 & $-2.244(1.168)$ & 0.056 \\
\hline \multicolumn{5}{|l|}{ Socioeconomic } \\
\hline Income per capita $(\mathrm{R} \$)$ & $0.002(0.001)$ & 0.004 & $-0.001(0.001)$ & 0.058 \\
\hline Schooling (years) & $0.546(0.227)$ & 0.016 & $0.450(0.229)$ & 0.078 \\
\hline \multicolumn{5}{|l|}{ Biological } \\
\hline Age (years) & $-0.192(0.101)$ & 0.059 & $-0.241(0.100)$ & 0.017 \\
\hline \multicolumn{5}{|c|}{ Pre-gestational nutritional status (BMI) } \\
\hline Normal & 1 & & & \\
\hline Underweight & $2.169(2.915)$ & 0.458 & $1.790(2.869)$ & 0.053 \\
\hline Overweight & $-0.147(1.365)$ & 0.914 & $0.426(1.343)$ & 0.751 \\
\hline Obesity & $-0.397(1.704)$ & 0.816 & $-4.095(1.677)$ & 0.015 \\
\hline \multicolumn{5}{|l|}{ Lifestyle } \\
\hline \multicolumn{5}{|l|}{ Living with a partner } \\
\hline No & 1 & & & \\
\hline Yes & $4.393(1.899)$ & 0.022 & $-3.170(1.907)$ & 0.098 \\
\hline \multicolumn{5}{|l|}{ Occupational activity } \\
\hline No & 1 & & & \\
\hline Yes & $2.328(1.198)$ & 0.534 & $-2.172(1.197)$ & 0.071 \\
\hline \multicolumn{5}{|l|}{ Smoke } \\
\hline No & 1 & & & \\
\hline Yes, before pregnancy & $-3.688(2.171)$ & 0.091 & $-2.224(2.147)$ & 0.301 \\
\hline Yes, during pregnancy & $-1.644(2.171)$ & 0.449 & $4.938(2.147)$ & 0.022 \\
\hline \multicolumn{5}{|l|}{ Use of alcoholic beverages } \\
\hline No & 1 & & & \\
\hline Yes, before pregnancy & $0.175(1.856)$ & 0.933 & $0.639(1.854)$ & 0.731 \\
\hline Yes, during pregnancy & $-2.156(3.222)$ & 0.504 & $-0.478(3.218)$ & 0.882 \\
\hline Sleep (hours) & $0.316(0.262)$ & 0.229 & $0.132(0.262)$ & 0.615 \\
\hline Physical activity (MET.h/dia) & $-0.066(0.043)$ & 0.129 & $0.023(0.043)$ & 0.589 \\
\hline Domestic (MET.h/dia) & $-0.137(0.057)$ & 0.017 & $0.095(0.057)$ & 0.097 \\
\hline Leisure (MET.h/dia) & $-0.119(0.745)$ & 0.874 & $0.331(0.743)$ & 0.656 \\
\hline
\end{tabular}

${ }^{*}$ t-test for continuous variables.

SE: standard error. 
TABLE 3 - Estimates of the univariate model related to the physical and mental components. Santo André, São Paulo, 2012-2013.

\begin{tabular}{lcccc}
\hline \multirow{2}{*}{ Variables } & \multicolumn{2}{c}{ Mental Component } & \multicolumn{2}{c}{ Physical Component } \\
\cline { 2 - 5 } & Coefficient (SE) & p & Coefficient (SE) & p \\
\hline Occupational (MET.h/dia) & $-0.54(0.093)$ & 0.565 & $-0.135(0.097)$ & 0.165 \\
\hline Locomotion (MET.h/dia) & $0.042(0.072)$ & 0.056 & $-0.087(0.072)$ & 0.225 \\
\hline Sedentary (MET.h/dia) & $-0.03(0.238)$ & 0.991 & $-0.279(0.236)$ & 0.239 \\
\hline Physical activity level (PAL) & 1 & & & \\
\hline Low & 1 & & $1.897(1.726)$ & 0.273 \\
\hline Moderate & $-3.093(1.723)$ & 0.074 & & 0.283 \\
\hline Vigorous & $-1.134(1.524)$ & 0.458 & $1.644(1.526)$ & \\
\hline Practiced leisure physical activity during pregnancy & & & 0.554 \\
\hline Yes & $3.127(1.472)$ & 0.035 & $0.880(1.485)$ & \\
\hline
\end{tabular}

Finally, in multiple model, for each additional year of age, there was an average decrease of 0.291 in the mental component of quality of life. Moreover, being a user of the private health sector provided an increase of the mental component score. In multiple model, it was chosen health sector because of his colinearity with income and educational level. Even in, crude analysis women who engaged in some physical activity during pregnancy had a better mental component score, this variable did not keep statistically significant.

Based upon the model of factors associated with the physical component of health, with increasing age, there is a decrease in the physical component of quality of life and nutritional status (TABLE 4).

TABLE 4 - Multiple model, factors associated with mental and physical components. Santo André, São Paulo, 2012-2013.

\begin{tabular}{lccc}
\hline Variable & Coefficient & Standard error & p \\
\hline Mental component & & & \\
\hline Intercept & 52.949 & 2.754 & $<0.001$ \\
\hline Health sector (private) & 4.596 & 1.166 & $<0.001$ \\
\hline Age & -0.291 & 0.101 & 0.004 \\
\hline Physical component & & & $<0.001$ \\
\hline Intercept & 52.133 & 2.998 & \\
\hline Nutritional Status (BMI) & & & $<0.268$ \\
\hline Underweight & -3.254 & 2.928 & $<0.803$ \\
\hline Overweight & -0.333 & 1.333 & $<0.051$ \\
\hline Obesity & -3.343 & 1.700 & 0.036 \\
\hline Age & -0.223 & 0.106 & \\
\hline
\end{tabular}

\section{Discussion}

Based on the data presented in this study, the prevalence of physical activity is low, which was already reported by many studies ${ }^{15,16,21,22}$. Walking was the most common physical activity performed by the mothers. Furthermore, it was observed that the activities performed had an average duration of 30 minutes per session, two times per week with light intensity. In general, most women do not receive the recommended amount of exercise of 150 minutes of moderate physical activity per week for pregnant 
women without medical complications ${ }^{23,24}$. The practice of physical activity during pregnancy has been linked to a number of maternal health benefits. Increasing the populations' physical activity level is becoming a public health priority and is gaining increasing prominence.

In the present study, it was observed that the majority of women who were active during the gestational period considered their health to be very good or excellent. One possible explanation for this observation, as suggested by BARAKAT et al. ${ }^{25}$, is that physical activity improves the mother's perception of her health status. Because of the numerous biological and psychological changes that occur during pregnancy, many studies suggest that pregnant women are more susceptible to mental health problems ${ }^{26}$. The occurrence of symptoms related to depression, anxiety and stress are very common during this period. Having poor mental health makes the practice of physical activity for pregnant women less attractive ${ }^{27}$. However, the practice of physical activity is an important tool for improving a woman's psychological and mental state $e^{28 .}$

Aspects related to mental and physical health comprise the major domains assessed by the SF12. In this context, this questionnaire serves as an important tool for measuring a person's quality of life. With the data presented here, it was observed that women who practice some LTPA had a higher mental health component when compared with women who do not practice. Only in the univariate analysis were identified association. When performed multivariate analysis to physical activity loses its association with other more relevant factors.

In a longitudinal study conducted in Australia on 473 pregnant women, EMmANuEL et al..$^{29}$ found that social support and the presence of their partners were factors associated with better mental health and quality of life. Additionally, FisHer et al..$^{30}$ suggested that the mental health of pregnant women and their psychological functioning could vary with age. RicHEDWARDS et al. ${ }^{31}$ suggested that women who were single and experienced financial difficulties during pregnancy were more likely to have symptoms of depression. The studies cited above corroborate the data presented in this study, which demonstrated that the mental component of health was associated with income, living with a partner, type of health service, education level and presence of pathologies.

In Brazil, the Ministry of Health is responsible for proposing actions that lead to pregnant woman having better health and more frequent medical monitoring.
Many of these actions are related to prenatal care. In addition to medical appointments, educational measures are used to help inform pregnant women of all of the changes that occur during gestation. Pregnant women can receive health care from the Brazilian Unified Health System (SUS) or from private hospitals and clinics. However, in Brazil, there are many differences in prenatal care between public or private institutions related to the existence of many inequalities relating to coverage of attention to health ${ }^{32}$.

In the present study, women who utilised private health care services had higher levels of education and a higher income than women who utilised public health care services (data not showed). These information corroborate conclusions presented in the study by CoImbra et al. ${ }^{33}$, which showed that women with higher incomes and education levels received better prenatal care. Some of these observations were confirmed by SchмIDT et al. ${ }^{22}$ who found that age, number of pregnancies, having a higher income and living with partner influenced the practice of performing physical activity during pregnancy. Nonetheless, differences in prenatal care between sectors (public and private) can directly reflect the type of information that pregnant women receive throughout their pregnancy. Consequently, pregnant women's habits, lifestyle, practice of physical activities and health can be influenced by the information they receive. TAVARES et al. ${ }^{21}$, in a study involving 118 pregnant women served by the Family Health Strategy (FHS) in Campina Grande, noted that the cohort patterns of physical activity are inadequate from the beginning of pregnancy and extend into the third trimester. As justification for reducing this pattern, the authors point to the lack of incentives for physical activity by professionals caring for the pregnant women.

It is noteworthy that the mothers who received private health care had a higher mental component of health than those that received public health care, and these differences were associated with several factors. Having a better socioeconomic status and greater social support lead to improvements in other aspects and generated a better quality of life. Unfortunately, the socioeconomic differences present among the mothers using the two health services could be seen as determining factors for which there are differences related to quality of life and also to the practice of physical activity. Improving the accessibility and availability of resources and health services might decrease the differences in quality of life observed between the two sectors. 
In this study, the use of a questionnaire to evaluate perceived quality of life that was not specific to pregnant women may have been a limiting factor because it did not take into account the common symptoms of pregnancy. Another limitation was related to memory bias, once information was retrospective collected at postpartum period. In fact, main limitation of a cross-sectional, it was the impossibility of evaluate causality. Once it is identify association, but it was not possible affirm if quality of life is an exposition or a cause factor. Reverse causality should be pointed out as a possibility. For this it would be necessary future prospective study designs.

For a pregnant woman to have a quiet and uneventful pregnancy, it is extremely important that she adopt a healthy lifestyle for the health of her and her baby ${ }^{34}$. Research from VIGITEL 2012 (Brazilian Surveillance of Risk and Protective Factors for Chronic Diseases Telephone Survey) showed that $51 \%$ of the adult population (over 18 years) was above their ideal weight ${ }^{35}$. During pregnancy, excessive weight gain can increase the need for caesarean delivery and the risk of complications such as hypertension, gestational diabetes mellitus, postpartum weight retention and the development of obesity ${ }^{36,37}$. The primary reasons pregnant women do not exercise are decreased physical abilities, lack of information and lack of motivation ${ }^{38}$. Furthermore, NING et al. ${ }^{39}$ noted that having an active lifestyle before pregnancy may influence the maintenance of this lifestyle during pregnancy. The practice of physical activity should be associated with factors and conditions that lead women to adopt an active lifestyle. Strategies for promoting physical activity during pregnancy should also consider the possible barriers to this practice. It is noted that many women are unaware of the recommendations about physical activity during pregnancy, due to a lack of information and guidance from health professionals. Therefore, increased training of these professionals and better recommendations can increase awareness of the benefits of physical activity on maternal-foetal health and also the woman's quality of life. However, there are few specific studies that relate quality of life with physical activity during leisure time in pregnancy.

Although, some studies relate to physical activity during leisure time and quality of life in the present study other aspects have greater association. Future studies can provide a better insight into other aspects associated with quality of life during pregnancy. In addition to research aimed at analysing the pathologies that affect the quality of life of pregnant women, greater understanding of the social and psychological aspects of a person's quality of life should be taken into consideration.

Despite the loss of association between the practice of physical activity and quality of life when performed multivariate analysis improve knowledge about this association should contribute to future interventions in reducing sedentary habits and physical inactivity. Once beyond the instrumental attitude, as the knowledge of the physiological benefits of exercise, but also the affective attitude with the self-perception of improved health and quality of life, could contribute to the promotion and maintenance of regular physical exercise ${ }^{38}$. Although the socioeconomic characteristics have a greater association with the perception of women as the quality of life related to health, the promotion of physical activity in leisure time has the potential to improve the quality of life in studied socio-economic conditions.

\section{Acknowledgements}

CNPq Grant (246278/2012-9)

\section{Resumo}

Percepção de qualidade de vida e prática de atividade física no lazer durante a gestação

A prática de atividade física durante a gestação tem um papel importante relacionado à melhora de como a mulher percebe seu estado de saúde. 0 objetivo deste estudo foi investigar a relação entre a qualidade de vida percebida durante a gestação e a prática de atividade física no lazer. Trata-se de um estudo transversal com 187 puérperas. Um questionário retrospectivo foi administrado para obter informações sobre a gestação, 
sendo avaliado o padrão de atividade física e o estado de saúde. Para avaliar os aspectos relacionados à qualidade de vida foi utilizado o questionário SF-12. As análises estatísticas foram o teste t, qui-quadrado e análise de regressão linear múltipla. A partir dos resultados, observou-se que as mulheres ativas durante a gestação consideraram sua saúde como sendo boa ou excelente em comparação aquelas que não eram ativas ( $p=0,005,35,9 \%$ e 15,5\%, respectivamente). Mulheres ativas apresentaram um componente mental superior quando comparadas com aquelas que não praticavam $(p=0,035)$. Além disso, foi possível observar uma relação entre o componente mental com o serviço privado de saúde, renda, nível de educação, a doença e a presença de um companheiro. 0 componente físico foi relacionado com a idade materna, baixo peso ao nascer, obesidade e tabagismo durante a gravidez. Apesar da análise univariada mostrar uma associação positiva entre atividade física no lazer e o componente mental da qualidade de vida relacionada à saúde, essa associação perdeu sua significância quando inclusa a idade e cuidados setores de saúde. Estudos longitudinais devem ser desenvolvidos para medir os efeitos da atividade física na qualidade de vida.

Palavras-chave: Gestante; Atividade Física; Qualidade de Vida.

\section{References}

1. Bowling A. What things are important in people's live? The survey's judgments to the public to inform scales of health-related quality of life. Soc Sci Med. 1995;4(10):1447-62.

2. Smith KW, Avis NE, Assmann SF. Distinguishing between quality of life and health status in quality of life research. Qual Life Res. 1999;8(5):447-59.

3. Wolfe LA, Davies GAL. Canadian guidelines for exercise in pregnancy. Clin Obstet Gynecol. 2003;46(2):488-95.

4. Pivarnik JM, Chambliss HO, Clapp JF, Dugan SA, Hatch MC, Lovelady CA, et al. Impact of physical activity during pregnancy and postpartum on chronic disease risk. Med Sci Sport Exer. 2006;38(5):989-1006.

5. Montoya AAV, Orozco BL, de Plata ACA, Mosquera EM, Ramirez-Velez R. Aerobic exercise during pregnancy improves health-related quality of life: a randomized trial. Journal of Physiotherapy. 2010;56(4):253-8.

6. Granath $\mathrm{AB}$, Hellgren MS, Gunnarsson RK. Water aerobics angiograms sick leave due to low back pain during pregnancy. J Obstet Gynecol Neonatal Nurs. 2006;35:465-71.

7. Dertkigil MSJ, Cecatti JG, Sarno MA, Cavalcante, SR, Marussi EF. Variation in the amniotic fluid index following moderate physical activity in water during pregnancy. Acta Obstet Gyn Scan. 2007;86(5):547-52.

8. Yeo S. Prenatal stretching exercise and autonomic responses: preliminary data and a model for reducing preeclampsia. J Nurs Scholarsh. 2010;42(2):113-21.

9. Schlussel MM, Souza EBD, Reichenheim ME, Kag G. Physical activity during pregnancy and maternal-child health outcomes: a systematic literature review. Cad Saúde Pública. 2008;24(supl 4):531-44.

10. Prather H, Spitznagle T, Hunt D. Benefits of exercise during pregnancy. PM\&R: Journal of Injury, Function, and Rehabilitation. 2012;4(11):845-50.

11. Dempsey JC, Butler CL, Sorensen TK, Lee IM, Thompson ML, Miller RS, et al. A case-control study of maternal recreation physical activity and risk of gestational diabetes mellitus. Diabetes Res Clin Pr. 2004;66(2):203-15.

12. Sorensen TK, Williams MA, Lee IM, Dashow EE, Thompson ML, Luthy DA. Recreational during pregnancy physical activity and risk of preeclampsia. Hypertension. 2003;41(6):1273-80.

13. Penney DS. The effect of vigorous exercise during pregnancy. J Midwifery Womens Health. 2008;53(2):155-9.

14. Clapp III JF, Kim H, Burciu B, Schmidt S, Petry K, Lopez B. Continuing regular exercise during pregnancy: effect of exercise volume on fetoplacental growth. Am J Obstest Gynecol. 2002;186(1):142-7.

15. Evenson KR, Wen F. Prevalence and correlates of objectively measured physical activity and sedentary behavior among U.S. pregnant women. Prev Med. 2011;53(1-2):39-43.

16. Domingues MR, Barros AJD. Leisure-time physical activity during pregnancy in the 2004 Pelotas birth cohort study. Rev Saúde Pública. 2007;41(2):173-80.

17. Tendais I, Figueiredo B, Mota J, Conde A. Physical activity, health-related quality of life and depression during pregnancy. Cad Saúde Pública. 2011;27(2):219-28.

18. Stevens, JP. Power of multivariate analysis of variance tests. Psychological Bulletin. 1980;88(3):728-37. 
19. World Health Organization. Obesity: preventing and managing the global epidemic: report of a WHO consultation. Geneva: WHO; 2000.

20. Corbacho MI, Dapueto JJ. Assessment of functional capacity and quality of life of patients with rheumatoid arthritis. Rev Bras de Reumatol. 2010;50(1):31-43.

21. Tavares JS, Melo ASO, de Amorim MMR, Barros VO, Takito MY, Benício MHD, et al. Physical activity patterns in pregnant women attending the family health program of Campina Grande - PB. Rev Bras Epidemiol. 2009;12(1):10-9.

22. Schmidt MD, Pekow P, Freedson PS, Markenson G, Chasan-Taber L. During pregnancy physical activity patterns in a diverse population of women. J Womens Health. 2006;15(8):909-18.

23. Borodulin K, Evenson KR, Wen F, Herring AH, Benson A. Physical activity patterns during pregnancy. Med Sci Sport Exer. 2008;40(11):1901-8.

24. Haakstad LA, Bø K. Exercise in pregnant women and birth weight: a randomized controlled trial. BMC Pregnancy Childbirth. 011 set; $11:[7$ p.].

25. Barakat R, Pelaez M, Montejo R, Luaces M, Zakynthinaki M. Exercise during pregnancy improves maternal health perception: a randomized controlled trial. Am J Obstet Gynecol. 2011;204(5):[7 p.].

26. Marcus SM. Depression during pregnancy: rates, risks and consequences: motherisk update 2008. The Canadian Journal of Clinical Pharmacology. 2009;16(1):15-22.

27. Poudevigne $S$, Connor P. The review of physical activity patterns in pregnant women and their relantionship physicological to health. Sports Med. 2006;36(1):19-38.

28. Urizar Junior GG, HurtS SQ, Albright CL, Ahn DK, Atienza AA, King AC. Influence of maternal stress on successful participation in a physical activity intervention: the Impact project. Women Health. 2006;42(4):63-82.

29. Emmanuel E, St John W, Sun J. Relationship between social support and quality of life in childbearing women during perinatal period. J Obstet Gynecologic Neonatal Nursing. 2012 ago;41:62-70.

30. Fisher J, Wynter K, Hammarberg K, Mcbain J, Gibson F, Boivin J, et al. Age, mode of conception, pregnancy and health serve use health: a prosprective cohort study of Australian women. BMC Pregnancy and Childbirth. 2013 abr;13:[13 p.].

31. Rich-Edwards JW, Kleinman K, Abrams A, Harlow BL, Mclaughlin TJ, Joffe H, et al. Sociodemographic predictors of antenatal and postpartum depressive Symptoms among women in a medical group practice. J Epidemiol Community Health. 2006;60(3):221-7.

32. Victora CG, Barros FC. Infant mortality due to perinatal causes in Brazil: trends, regional patterns and possible interventions. São Paulo Medical Journal. 2001;119(1):33-42.

33. Coimbra LC, Silva AA, Mochel EG, Alves RV, Aragon VMF, Bettiol H. Factors associated with the utilization of prenatal care. Rev Saúde Pública. 2003;37(4):456-62.

34. Amezcua-Prieto C, Olmedo-Requena R, Jimenez-Mejias E, Mozaz-Moreno J, Lardelli-Claret P, Moleon-Jimenez JJ. Factors associated with changes in leisure time physical activity during early pregnancy. Int J Gynecol Obstet. 2013;121(2):127-31.

35. Ministério da Saúde. Vigitel Brasil 2012: vigilância de fatores de risco e proteção para doenças crônicas por inquérito telefônico. Brasília: Ministério da Saúde; 2013.

36. Roessner S. Physical activity and prevention and treatment of weight gain associated with pregnancy: current evidence and research issues. Med Sci Sport Exer. 1999;31(supl 11):5613.

37. Nehring I, Schmoll S, Beyerlein A, Hauner H, von Kries R. Gestational weight gain and long-term postpartum weight retention: a meta-analysis. Am J Clin Nutr. 2011;94(5):1225-31.

38. da Costa D, Ireland K. Perceived benefits and barriers to leisure-time physical activity during pregnancy in previously inactive and active women. Women Health. 2013;53(2):185-202.

39. Ning Y, Williams MA, Dempsey JC, Sorensen TK, Frederick IO, Luthy DA. Correlates of recreational physical activity in early pregnancy. J Matern Fetal Neonatal Med. 2003;13(6): 385-93.

ENDEREço
Ana Claudia Hirasawa
Escola de Educação Física e Esporte da
Universidade de São Paulo
Av. Prof. Melo Moraes, 65 - Cidade Universitária
O5508-O3o - São Paulo - SP - BRASIL
e-mail: anaclaudia.mayumi@gmail.com

Submitted: 08/04/2015

Review: 03/08/2015

Accepted: 15/12/2016 